\title{
TRAYECTORIAS DE POLITIZACIÓN: LA ESTRATEGIA DEL SINDICATO CERAMISTA NEUQUINO, 2001-2003
}

FERNANDO AIZICZON (CONICET-IDH),

Instituto de Humanidades, Facultad de Filosofía y Humanidades, Universidad Nacional de Córdoba, feraizic@gmail.com

\section{Resumen:}

Este trabajo se aproxima al estudio del proceso de lucha del sindicato ceramista de Neuquén (SOECN) entre la crisis sociopolítica del año 2001 hasta fines del año 2003. Dicho proceso, que denominamos trayectoria de politización, permite discutir las transformaciones que atraviesan los trabajadores en el transcurso de una lucha política que posibilita la construcción de estrategias y acciones innovadoras abriendo la discusión sobre la función de la organización sindical más allá del sindicato.

Palabras clave:

Trayectorias de politización - Estrategia - Sindicato ceramista - Neuquén

\section{Trajectories of politicization: the strategy of Neuquén ceramist union, 2001-2003}

\begin{abstract}
:
This paper approaches the study of the process of struggle of the ceramist union Neuquén (SOECN) between the sociopolitical crisis of 2001 until the end of 2003. This process, which we call trajectory of politicization, it lets discuss the changes faced by workers in the during a political struggle that enable the construction of innovative strategies and actions opening the discussion on the role of the trade union beyond the union.
\end{abstract}

\section{Keywords:}

Trajectories of Politicization - Strategy - Ceramist Trade Union - Neuquén 


\title{
TRAYECTORIAS DE POLITIZACIÓN: LA ESTRATEGIA DEL SINDICATO CERAMISTA NEUQUINO, 2001-2003
}

\author{
FERNANDO AIZICZON (CONICET-IDH), \\ feraizic@gmail.com
}

\section{Trayectoria, estrategia y politización de trabajadores}

En la historia argentina reciente el fenómeno de la politización de trabajadores que atraviesan experiencias de lucha constituye un terreno de estudios que presenta diversos enfoques. La mayoría de ellos se inscribe en torno al debate sobre la "revitalización sindical" y coincide en tomar el año 2003 como inicio de un fuerte ascenso de la protesta gremial donde los trabajadores formales volvieron a ser los principales protagonistas del conflicto social en un contexto con menor desocupación que en la década precedente pero con altos niveles de informalidad y precariedad laboral ${ }^{1}$. Estas investigaciones han abordado aspectos como la dimensión territorial del activismo sindical ${ }^{2}$, el impacto del 2001 en nuevas generaciones obreras ${ }^{3}$, el resurgir del clasismo o del denominado sindicalismo de base ${ }^{4}$ y el activismo sindical en lugares como call centers y supermercados ${ }^{5}$, es decir, la politización es entendida como la emergencia y conformación de núcleos activos de trabajadores (activismo) que despliegan diversas formas de militancia sindical.

Investigaciones previas realizadas en otros países han señalado la importancia de analizar estrategias políticas territoriales desarrolladas por sindicatos que incorporan demandas de trabajadores informales y desocupados, lo cual amplía la discusión y el sentido de la politización hacia el terreno de las alianzas políticas desarrolladas por estos actores aunque bajo la denominación de "sindicalismo de movimiento social" (Social-Movement Unionism), término sintomático que indica también la necesidad de brindar una respuesta desde los sindicatos a la pérdida de afiliados, al dilema sobre la representación de intereses, a la declinación de la capacidad de movilización, al debilitamiento de los vínculos con los partidos políticos, etcétera. En efecto, este último tipo de sindicalismo busca desplegar acciones conjuntas con organizaciones sociales no sindicales, donde el sindicato juega el papel de actor social "viejo" o

\footnotetext{
1 Azteni, Mauricio y Ghigliani, Pablo, "The re-emergence of workplace based organisation as the new expression of conflict in Argentina", en Gall, G., New Forms and Expressions of conflict at work, Palgrave Macmillan, 2013; Palomino, Héctor, "Un nuevo indicador del Ministerio de Trabajo, Empleo y Seguridad Social: Los Conflictos Laborales en la Argentina 2006-2007”, Buenos Aires: Trabajo, Ocupación y Empleo, No 7, 2007.

2 Elbert, Rodolfo, "Activismo sindical y territorio en un período de reactivación de la protesta gremial en Argentina: Estudio de caso de trabajadores de un frigorífico ubicado en la zona norte del Gran Buenos Aires (2010-2011)", en Quid 16, N² (181-192), Buenos Aires, 2012.

${ }^{3}$ Varela, Paula, La disputa por la dignidad obrera. Sindicalismo de base fabril en la zona norte del Conurbano bonaerense, $2003-$ 2014, Buenos Aires, Imago Mundi, 2015.

${ }^{4}$ Duhalde, Santiago y Lenguita, Paula, "El clasismo sindical en tiempos kirchneristas. Un estudio de caso", en revista Conflicto Social, Año 5, № 7, Buenos Aires, 2012.

${ }^{5}$ Abal Medina, Paula, Ser sólo un número más. Trabajadores jóvenes, grandes empresas y activismos sindicales en la Argentina actual, Buenos Aires, Biblos, 2014.

${ }^{6}$ Moody, Kim, Workers in a Lean World. Unions in the International Economy. Londres, Verso, 1997; Frege, Carola y Kelly, John, "Union Revitalization Strategies in Comparative Perspective", London: European Journal of Industrial Relations, vol 9, 7-24, 2003; Ferrero, Juan Pablo y Gurrera, María, "El sindicalismo de movimiento social. Algunas reflexiones en torno del concepto", en Fernández, Arturo (comp.) Estado y sindicatos en perspectiva latinoamericana. Buenos Aires, Prometeo, 2007.
} 
tradicional a la par de "nuevos" movimientos sociales, quedando en suspenso la cuestión del "sujeto" que hegemonizaría dicha alianza. Un ejemplo de lo anterior se puede encontrar en la experiencia de algunos sindicatos en Sudáfrica, Corea del Sur, Europa, EEUU, y más cerca nuestro, en la CUT - Central Única dos Trabalhadores brasilera o la CTA - Central de Trabajadores de la Argentina, que se construyó como una central de trabajadores que buscó engrosar sus filas estableciendo alianzas con otras organizaciones por fuera del sector formal: comunidades indígenas, asociaciones de usuarios, asociaciones de meretrices, cooperativas de viviendas, trabajadores desocupados, asociaciones barriales, etcétera.

Finalmente, en el extremo izquierdo del espectro de politización encontramos el mencionado sindicalismo de base que suele asociarse (o confundirse) con sindicalismo clasista, aunque entre ambos existen matices importantes. El primero ha sido registrado a partir del año 2004 en la zona norte del conurbano bonaerense (fábricas Fate, Kraft, Mafissa, Praxair) y en algunas seccionales de trabajadores del Subterráneo y de docentes (Suteba); sus principales rasgos serían la irrupción desde las bases de nuevas generaciones de jóvenes que cuestionan las prácticas sindicales (acusadas de "burocráticas", de allí también que se lo denomine como "sindicalismo antiburocrático"), la democratización del espacio laboral (realización de asambleas, conformación de comisiones internas) y la presencia del activismo de izquierdas combinado con el de militantes independientes ${ }^{7}$. El segundo caso remite a una tradición histórica surgida entre los años de 196070 principalmente en Córdoba, y cuyos rasgos pueden resumirse -además del factor generacional, el efecto democratizador y la presencia de corrientes de izquierda- en la predisposición a la acción directa (tomas y ocupaciones de fábricas con rehenes, por ejemplo), la incorporación de un discurso anclado en la lucha de clases que enfatizaba la puja capital-trabajo, y la prefiguración de un horizonte político socialista puesto en juego en la construcción de alianzas estratégicas con organizaciones de izquierda. Es decir, comparado con el sindicalismo de base actual y sin considerar los diferentes contextos temporales, el clasismo histórico implica una marcada politización hacia la izquierda del colectivo obrero; politización que es resultado de un proceso que pone en juego discusiones ideológicas, formulaciones programáticas y prácticas sindicales disruptivas $^{8}$; y si bien la referencia histórica es una tentación ineludible que suele provocar equívocos, el caso que presentamos a continuación indicaría tanto un rescate de esa tradición como una ampliación innovadora de la misma ${ }^{9}$. En este último sentido, nos interesa aquí interrogarnos en cómo la lucha que los obreros ceramistas agrupados en el SOECN (Sindicato de Obreros y Empleados Ceramistas de Neuquén) dieron durante los años 2001-2003 significó un momento decisivo para la construcción del perfil combativo ceramista, considerando para ello las diferentes posiciones políticas y alianzas que elaboraron y, por otro lado, indagando en cómo esas

\footnotetext{
${ }^{7}$ Ver Varela, Paula, op. cit.

8 El clasismo ha sido ampliamente investigado desde diversas perspectivas. Entre los principales estudios ver Gordillo, Mónica, Córdoba en los '60. La experiencia del sindicalismo combativo. Córdoba, Universidad Nacional de Córdoba, 1999; Brennan, James, El Cordobazo. Buenos Aires, Sudamericana, 1996; Schumcler, Maleki, Gordillo, El obrerismo de pasado y presente. Documentos para un dossier (no publicado) sobre SITRAC-SITRAM. Buenos Aires, ediciones Al margen, 2010; Duval, Natalia, Los sindicatos clasistas. Buenos Aires, CEAL, 1988; Flores, Gregorio, SITRAC-SITRAM. La lucha del clasismo contra la burocracia sindical. Córdoba, ed. Espartaco, 2004; Werner, Ruth y Aguirre, Facundo, Insurgencia obrera en la Argentina (1969-1976). Clasismo, coordinadoras interfabriles y estrategias de la izquierda. Buenos Aires, Ediciones IPS, 2007; Löbbe, Héctor, La guerrilla fabril. Clase obrera e iqquierda en la Coordinadora de Zona Norte del Gran Buenos Aires (1975-1976), Buenos Aires, Ediciones Razón y Revolución, 2006.

${ }_{9}^{9}$ Recientemente se ha escrito sobre experiencias radicales desarrolladas después del 2009 en España, Francia, Grecia, Inglaterra y que si bien son minoritarias superan los marcos políticos de compromiso del "sindicalismo de movimiento social"; de allí que se las denominen como "sindicalismo radical" (radical political unionism) en base a tres rasgos observados: combatividad, lugar de trabajo como espacio organizacional pero articulado con otros sectores sociales, y un marcado posicionamiento político hacia la izquierda. Ver Upchurch, Martin y Mathers, Andy, "Neoliberal Globalization and Trade Unionism: Toward Radical Political Unionism”, en Critical Sociology 38 (2): $265-$ 2870, London, 2011.
} 
posiciones iluminan un trayecto de politización que lleva a inscribirlos en la tradición del clasismo.

En varios artículos previos hemos estudiado a los obreros ceramistas respecto del origen de la resistencia sindical y la posterior elección del control obrero como formato de autogestión hasta inicios del año 2002, también exploramos la influencia del trotskismo en los rasgos generales de la política del SOECN. Sin embargo, y a pesar del enorme interés que ha registrado esta experiencia tanto en el campo académico como en el campo militante, incluida principalmente en el universo de las denominadas "fábricas recuperadas" y por lo tanto descuidando la cuestión sindical", persiste un vacío al momento de estudiar cómo se construyó el sistema de alianzas originales, qué actores la protagonizaron, qué estrategia ensayaron y cuál fue la suerte de estos años iniciales de la experiencia ceramista ${ }^{11}$.

Para dar cuenta del cómo ocurrió este proceso utilizamos la idea de trayectoria propuesta por Bourdieu ${ }^{12}$ cuando refiere, discutiendo al relato biográfico idealizado, a la serie de posiciones sucesivamente ocupadas por un mismo grupo dentro de una red de relaciones objetivas, agregando el sentido dinámico que le otorgan Tilly, Tarrow y Mc Adam a los episodios de enfrentamiento o contienda política, esto es, la explicación del curso (trayectoria) que toma una lucha incluyendo su impacto fuera de las interacciones inmediatas. ${ }^{13}$ Una trayectoria así expuesta, como veremos, no se despliega en el vacío sino que sugiere también la elaboración de estrategias en el sentido de una perspectiva a largo plazo que oriente la acción y que incorpore, a su vez, un horizonte político que se define en sucesivas contiendas: una trayectoria de politización. Allí se juegan la construcción de un "nosotros", de un antagonista o enemigo, y las posibilidades de establecer alianzas, entre otros aspectos que reenvían a la cuestión de cómo se interpretan y redefinen las demandas de los actores involucrados, contemplando la posibilidad de pensar a los sindicatos como agentes estratégicos dotados de una capacidad para aprender y reflexionar sobre su historia reciente. ${ }^{14}$

Ofrecemos a continuación una descripción histórica que busca reconstruir los años iniciales de una trayectoria de politización (2001-2003) a través del análisis de fuentes documentales primarias

\footnotetext{
${ }^{10}$ Pueden consultarse los estudios ya clásicos sobre fábricas recuperadas y que incluyen a los ceramistas de Zanón en aquel campo de indagaciones, Fajn, Gabriel, Fábricas y empresas recuperadas. Protesta social, autogestión y rupturas en la subjetividad. Buenos Aires, Instituto Movilizador de Fondos Cooperativos, 2003; Rebón, Julián, La Empresa de la Autonomía: Trabajadores recuperando la producción. Buenos Aires, Ediciones Picaso, 2007; Novaes, Henrique, O fetiche da tecnologia: a experiência das fábricas recuperadas, Brasil, Expressão Popular, 2007; Programa Facultad Abierta, Las empresas recuperadas en la Argentina: Informe del segundo relevamiento del Programa Facultad Abierta. Buenos Aires, Secretaría de Extensión Universitaria, Facultad de Filosofía y Letras, UBA, 2005; Observatorio Social sobre Empresas Recuperadas y Autogestionadas (OSERA), disponible en: http://www.empresasrecuperadas.org/revista.php.

${ }^{11}$ Ver Aiziczon, Fernando, Zanón. Una experiencia de lucha obrera. Buenos Aires, ed. Herramienta, 2009; Zanón. Fábrica sin patrones, Chile, ed. Escaparate, 2015; "El clasismo revisitado. La impronta del trotskismo en la politización del sindicato ceramista: Zanón Bajo Control Obrero, Neuquén 1998-2006”, en LabourAgain Publications, Nederlands, 2007, disponible en: http://www.iisg.nl/labouragain/documents/aiziczon.pdf. Otros autores han referido diversos aspectos de la experiencia ceramista, ver Patrouilleau, Mercedes, "Historicidad e identidad colectiva en la gestión obrera de Zanón, Neuquén", Tesis de Maestría, Buenos Aires, UBA, 2009, disponible en: http://biblioteca.clacso.edu.ar/Argentina/iigg-uba/20130911022619/Patrouilleau Tesis.pdf; Freire, Jorgelina, "La participación de las mujeres en las fábricas recuperadas: el caso de la Cerámica Zanón, Neuquén 2000-2006.”, Neuquén, 2008, disponible en: http://www.hechohistorico.com.ar/Trabajos/Jornadas $\% 20$ de $\% 20$ Bariloche $\% 20$ \%202008/Freire.pdf; Kejner, Emilse, "Tomar la fábrica: producir alternativas. Análisis de las asambleas y las relaciones de género en los discursos fílmicos sobre Zanón - FaSinPat”, en 3as Jornadas de Historia de la Patagonia San Carlos de Bariloche, 2008.

12 Bourdieu, Pierre, Razones prácticas, España, Anagrama, 1977.

13 Tilly, Charles; Tarrow, Sidney y Mc Adam, Dough, Dynamics of contention, Cambridge University Press, 2001.

${ }^{14}$ Hyman, Richard, “¿How trade unions act strategically?”, en European Review of Labour and Research, 13 (2), pp. 193$210,2007$.
} 
tales como libros de actas sindicales y boletines, que consideramos una entrada privilegiada a cómo se construyen las definiciones políticas desde los mismos protagonistas.

\section{E1 SOECN: de la experiencia burocrática a la construcción del militante antiburocrático}

En diciembre del año 2000 se produce el traspaso de autoridades en el Sindicato de Obreros y Empleados Ceramistas de Neuquén (SOECN). Los resultados electorales arrojaron 206 votos para la Lista Marrón y 120 para la Lista Verde (oficialista) ${ }^{15}$. La historia del SOECN se inicia en 1983; hacia entonces, apenas 200 afiliados $^{16}$ que agrupan a 4 fábricas de cerámicos, ladrillos huecos y revestimientos constituyen el novel sindicato: Cerámica Zanón se inaugura a fines de los '70 y es la mayor y más tecnologizada. Zanón fue además uno de los 50 mayores proyectos de inversión beneficiados por leyes de promoción industrial en tiempos de dictadura militar ${ }^{17}$. Hacia 1993 esta fábrica incorpora una moderna sección de porcellanato que incrementa su capacidad operativa y su personal obrero, que para el año 2000 posee cerca de 800 trabajadores, lo que la posiciona como la fábrica más grande y con mayor cantidad de obreros de todo Neuquén, provincia cuya principal y estratégica actividad se concentra exclusivamente en la extracción de recursos hidrocarburíferos (petróleo y gas). A menos de 100 metros se encuentra Cerámica Neuquén, unos años más joven que Zanón, y con apenas un centenar de obreros. Ya en las afueras del Parque Industrial de Neuquén se ubica Cerámica del Valle, la más antigua de todas. Fabrica ladrillos huecos, emplea a menos de 50 obreros y su tecnología no experimenta modificaciones desde su fundación. A más de 100 kilómetros de Neuquén capital, en la ciudad de Cutral Có, se encuentra Cerámica Stefani, de características similares a la anterior en cuanto a tecnología y personal.

El SOECN se encuadra como filial 21 de la FOCRA (Federación de Obreros Ceramistas de la República Argentina). Ésta, desde la asunción de la nueva conducción se mostró hostil a los reclamos de los ceramistas neuquinos respecto a deudas de alquileres de sucursales del SOECN, faltantes de documentación legal, ausencia de balances, cheques emitidos sin fondos, apropiación de un automóvil a nombre del titular del sindicato, cuentas bancarias cerradas, entre otras irregularidades ${ }^{18}$. Tras casi 20 años de funcionamiento apenas un tercio de los obreros ceramistas neuquinos estaba afiliado al SOECN y, como revelan los datos electorales del año 2000, sólo deciden su representación algo más que 300 trabajadores. Sin embargo, este recambio en la conducción del sindicato implicó el cierre de un primer ciclo de luchas circunscripto al interior de la fábrica de cerámicos Zanón, que aportó la mayoría del padrón del SOECN, donde la recuperación de la comisión interna (CI) en 1998 significó la realización de elecciones tras largos años sin esa instancia de organización de base. Hasta entonces los obreros carecían de CI y se encontraban sin representación frente a los ataques de la patronal, pero también de cara al accionar de lo que los obreros ya denominan como la "burocracia" del SOECN a cuya cabeza se encuentra, desde la fundación del sindicato, Alberto Montes, un sindicalista sin identificación partidaria pero señalado por los obreros como afín a los intereses patronales. Despidos, atrasos salariales, malas condiciones laborales, entre otros aspectos fueron revertidos a través de la acción directa. Por caso, la constitución de la CI y la fundación de la Lista Marrón que la representa se encuadran en un clima previo de "fábrica tumba", sin discusión política, con un pasado reciente de listas de activistas que intentan organizarse pero son despedidos o "arreglan" su retiro de la

\footnotetext{
${ }^{15}$ Libro de Actas Junta Electoral SOECN, Folios 1-33.

${ }^{16}$ Registro de afiliados, Ministerio de Trabajo, Dirección Nacional de Asociaciones Gremiales, Departamento de Personerías e Inscripciones, FOCRA Neuquén, 1983, Tomo I.

17 Ver Azpiazu, Daniel y Basualdo, Eduardo, Cara y contracara de los grupos económicos. Estado y promoción industrial en Argentina. Buenos Aires, Ed. Cántaro, 1990.

18 Ver informe de Mariano Pedrero, abogado del SOECN, "Administración fraudulenta y Fraudes varios", Neuquén, s/f.
} 
fábrica con la patronal, o consideran imposible vencer al oficialismo de Montes. ${ }^{19}$ Enfrentar a la burocracia, resistir las medidas de la patronal y fundamentalmente evitar un arreglo que anule todo intento de cambio llevará a poner en juego la implementación de una serie de valores y prácticas nuevas que inicialmente fueron dos: a) ningún dirigente, de asumir, puede "arreglar"; y b) "una asamblea nos pone, una asamblea nos saca" 20 . En las primeras discusiones de la flamante nueva Comisión Directiva (CD) del SOECN estas propuestas se someten a votación generando un consenso sobre las prácticas sindicales válidas y diferenciadas de las prácticas "burocráticas" que irán consolidando un perfil determinado: "Por mayoría se resuelve que ningún dirigente queda autorizado a realizar alguna reunión en forma personal con las empresas, donde por lo menos tienen que concurrir dos dirigentes" ${ }^{\text {"21. }}$.

Estas nuevas prácticas ya vienen desde discusiones previas a las elecciones del año 2000, cuando dentro de la Lista Marrón se traza una suerte de "programa mínimo" que se complejizará incorporando los siguientes puntos: 1) igual salario, igual trabajo, 2) democracia obrera, 3) decisiones en asamblea, 4) revocabilidad de mandatos, 5) pase a planta permanente de todos los contratados, 6) delegados por sector para construir un cuerpo de delegados. ${ }^{22}$ Este conjunto de demandas se explica tanto por el rechazo a las prácticas de la anterior conducción sindical como por la influencia creciente del activismo de izquierdas, que distribuye sus materiales de prensa en el portón de fábrica y también posee activistas que despliegan su liderazgo, tal el caso de Raúl Godoy, militante trotskista, que confluye con Alejandro López, un obrero sin militancia política pero reconocido por sus pares como organizador de eventos como asados o campeonatos de fútbol. La militancia encuadrada en partido político (Godoy) distinguirá en breve a los obreros de izquierda frente a los obreros sin filiación partidaria o que son mejor conocidos en la jerga ceramista y militante como los "independientes" (López). Esta distinción resulta central a la hora de ponderar las tensiones internas que redefinen permanentemente los difusos límites inherentes a esta experiencia, recurrentes tanto en Zanón como en la historia del clasismo como corriente sindical. ${ }^{23}$

Godoy y López convergerán en la CI que luego es el núcleo militante que recupera el SOECN; en el trascurso de esas luchas ambos se transformarán en los máximos referentes de esta experiencia. Ambos comparten rasgos generacionales (López tiene 30 años al asumir como secretario adjunto, mientras que Godoy tiene 35 cuando accede a la conducción del SOECN); este rasgo etario se expande hacia la mayoría del cuerpo directivo del SOECN y alcanza a quien será el nuevo abogado que asesore al sindicato, Mariano Pedrero, también militante trotskista y compañero de Godoy en el Partido de los Trabajadores Socialistas (PTS) ${ }^{24}$. Su posición estratégica será decisiva para afianzar, legitimar e incluso prestigiar la intervención del PTS en la fábrica, y su "saber experto" servirá no sólo para presentar opciones alternativas frente a las

${ }^{19}$ La "Lista Marrón" gana en 1998 las elecciones para comisión interna alcanzando los 187 votos, frente a la "Lista Roja" con 83 votos y la "Lista Verde y Azul" con 47 votos. Esta última es la lista oficialista, mientras que la Lista Roja, según testimonios de los obreros, fue armada entre la empresa y el sindicato para sacarle votos a la Marrón bajo el slogan de "ni burocracia ni combatividad". Ver Aiziczon, Fernando, Zanón. Una experiencia de lucha obrera, Buenos Aires, ed. Herramienta, 2009.

${ }^{20} \mathrm{El}$ proceso de irrupción de una generación de jóvenes que se politizan y disputan exitosamente la conducción del SOECN está desarrollado en Aiziczon, Fernando, Zanón...cap. VI.

Ídem, p. 147.

${ }^{21}$ Libro de Actas de Asambleas del SOECN, Ministerio de Trabajo, Formación y Empleo, Agencia Territorial Neuquén, Acta $N^{\circ} 1,13 / 12 / 2000$, Folio 2 (en adelante usamos número de acta, fecha y folio).

22 Aiziczon, Fernando, Zanón... op. cit.

23 Para una problematización de la identidad en Zanón ver Patrouilleau, Mercedes Historicidad e identidad colectiva en la gestión obrera de Zanón, Neuquén, op. cit.

${ }^{24}$ El PTS es un desprendimiento del MAS (Movimiento al Socialismo), partido fundado en 1983. El MAS se desintegra hacia 1991. Ambos partidos hunden sus raíces en el "morenismo" (del que luego el PTS se distanciará), en alusión su máximo referente, Nahuel Moreno (1924-1987) fundador del Grupo Obrero Marxista (GOM) en 1944 caracterizado por su clara inclinación "obrerista". 
maniobras patronales sino fundamentalmente para habilitar el camino de la acción directa cuando los reclamos obreros no sean escuchados, demostrando al mismo tiempo que su propia práctica puede encuadrarse en la de un sindicato combativo. Al asumir sus funciones como abogado del SOECN leemos:

"Su forma de trabajar [Mariano Pedrero] es la lucha porque cree que es la única forma de defender los derechos de los trabajadores, y que si en algún momento esta comisión directiva se vuelve burócrata, él se preserva el derecho de seguir o no." ${ }^{25}$

Como puede leerse, la noción de "burócrata" se convierte en un parteaguas a la hora de jurarse fidelidad al proyecto en marras; pero aquella noción necesita desarrollar su contraparte: el clasista. A su vez, el clasismo es una noción más integral que todavía requiere, para emerger con fuerza, del ingreso de otras nociones y prácticas previas, de allí que sea más preciso hablar en este momento inicial de antiburocratismo. A su turno, para que el sentimiento antiburocrático sea más fuerte y exceda al ámbito del discurso político necesita encarnarse en las prácticas organizativas, como por ejemplo, en paralelo a la organización institucional del SOECN emergen "grupos gremiales" de finanzas, de prensa y difusión, de fondo de huelga, entre otros, es decir, la existencia de un orden institucional (el sindicato) no invalida el funcionamiento "de base", al contrario, necesita estimularlo porque funciona de reaseguro al burocratismo. Sin embargo, este estímulo al funcionamiento "de base" no implica un relajamiento de la disciplina militante, al contrario, requiere el ejercicio de un control estricto de esa actividad, en otras palabras, el antiburocratismo es tanto una práctica opuesta a la traumática experiencia previa como también un nuevo modo de generar reaseguros normativos. Un ejemplo de esto puede encontrarse en la discusión sobre el uso de horas gremiales:

"para que un dirigente de la comisión directiva y comisión revisora de cuentas cobre las horas gremiales, deberá presentar una planilla que les proveerá el gremio donde conste qué es lo que hizo, fecha y horas que perdió en su fábrica para realizar tareas gremiales. Esto servirá para que las cosas sean transparentes y para que nadie se abuse de sus fueros y para que también cualquier afiliado que quiera saber qué hizo su dirigente pueda acceder rápidamente a la respuesta." 26

Otras prácticas consideradas por los obreros como antiburocráticas son la realización de plenarios abiertos a activistas y delegados extra sindicales (partidos de izquierda y organizaciones de $\mathrm{DDHH}^{27}$ ), la realización sistemática de asambleas de CD abiertas a miembros de la CI (más de una asamblea por mes), la asistencia permanente del abogado (que permite aceitar acción directa con disputa legal), o la práctica de asambleas "en caliente", es decir, en las diferentes fábricas en conflicto que conforman el SOECN. En suma, un dirigente antiburocrático es por antonomasia un dirigente honesto (no "arregla" con la patronal) que se somete a las nuevas reglas del control militante. En el mismo sentido, el atributo de la honestidad del dirigente como valoración positiva se comprende junto al largo historial de obreros "comprados" por la patronal para desactivar la resistencia o desalentarla en virtud de los montos dinerarios ofrecidos en escandalosos "arreglos". El impacto de este atributo es tan grande que se coloca muy por encima de la valoración política del dirigente, y que en esta etapa inicial no necesariamente es de izquierda.

\footnotetext{
25 Acta $\mathrm{N}^{\circ} 2,27 / 12 / 2000, \mathrm{~F} .8$, negritas nuestras.

${ }^{26}$ Acta No6, 09/02/2001, F. 24.

27 Por cuestiones de orden ideológico, estos plenarios abiertos excluyen de hecho la presencia de partidos tradicionales como la UCR, PJ y el local y oficialista Movimiento Popular Neuquino (MPN), de sólidos lazos con la patronal de Zanón. El carácter "abierto" debe entenderse entonces como de apertura a organizaciones sociales y políticas combativas y predominantemente de izquierda.
} 


\section{Alianzas estratégicas: el modelo político de la Coordinadora Regional Alto Valle y Neuquén}

El SOECN también debió lidiar con conflictos en las restantes cerámicas, sobre las cuales se intenta replicar la estrategia de lucha pero resulta difícil por la poca predisposición a la acción, por el miedo a más despidos o por la incertidumbre sobre la estrategia patronal: Cerámica Stefani (Cutral Có) durante el año 2001 ingresa a concurso de acreedores, adeuda aguinaldo, repite atrasos salariales y es intimada por el Ministerio de Trabajo que la sanciona con actas de infracción ${ }^{28}$. Cerámica Del Valle, una fábrica pequeña y precaria que emplea una veintena de obreros, también adeuda aguinaldo y salarios, mientras su dueño amenaza con cerrarla, lo que ocurrirá a fines del 2001 cuando despida a todo su personal. Cerámica Neuquén, ubicada al costado de Zanón, también se atrasa con los salarios mientras los obreros sufren recortes en las raciones que sirve del comedor.

Mientras, los obreros de Cerámica Zanón atraviesan exitosamente lo que denominan la "huelga de los 34 días" (mayo-abril de 2001) que logra frenar despidos y que consolida políticamente a la $\mathrm{CD}$ del $\mathrm{SOECN}{ }^{29}$ que a su vez comienza a construir una alianza con organizaciones que ya se habían mostrado solidarias con su lucha. En este sentido podemos distinguir dos espectros de alianzas: una desplegada a través de la intervención de las organizaciones sindicales y partidos de izquierda y otra vinculada a las redes comunitarias y de sociabilidad preexistentes en los ceramistas (barrios, escuelas, bibliotecas populares). Entre ambas también podemos ver actores intermedios como Radio Universidad, referentes de la comunidad mapuce, entre otros. La interacción entre redes comunitarias y organizaciones políticas suele sobreponerse en momentos de máxima tensión, mientras que cuando prima el tiempo político lo comunitario retrocede. Durante las "huelga de los 34 días", por ejemplo, emergió el Comité de lucha de Centenario, constituido por Zanón, la seccional Centenario de la Asociación de Trabajadores de la Educación de Neuquén (ATEN, donde militan esposas de algunos ceramistas) y la biblioteca popular Fonseca.

La solidaridad de organizaciones de izquierda ya se presentaba desde agrupaciones estudiantiles y de DDHH ligadas al PTS como En clave Roja o el Centro de Profesionales por los Derechos Humanos (CeProDh, desde donde interviene Mariano Pedrero), fundamentales para acercar a los obreros a la estratégica Universidad Nacional del Comahue (UNCo), mientras que los lazos comunitarios provenían de la ciudad de Centenario, cercana a la fábrica, de donde son oriundos muchos ceramistas, y puede rastrearse en acciones como caravanas de apoyo, o actividades realizadas por bibliotecas populares o centros vecinales.

Sobre esta red de solidaridades es que se genera una alianza estratégica construida desde el SOECN hacia afuera de la fábrica y se asienta en la percepción de que en soledad el conflicto puede peligrar, pero también se explica si indagamos en la visión del orden social que van elaborando los obreros. Luego de la "huelga de los 34 días" las discusiones dejan ver que "pronto se viene una guerra" ${ }^{\text {"30 }}$ o en palabras de Alejandro López, referente de la línea independiente:

"Tenemos que explicarles [a los compañeros] que se ganó este conflicto pero tenemos que tener cuidado e informarles que el resto de los empresarios junto con Zanón tienen preparado un plan nacional aprobado por el gobierno nacional."31

El secretario de prensa Carlos Acuña, también independiente, opina que:

\footnotetext{
${ }^{28}$ Acta $\mathrm{N}^{\circ} 3,06 / 01 / 2001$, F. 11.

${ }^{29}$ Un año antes, la indignación por la muerte del joven obrero Daniel Ferrás sin asistencia médica en la fábrica desató la "huelga de los 9 días" (julio de 2000), primer gran triunfo de esta nueva camada de activistas.

30 Acta $\mathrm{N}^{\circ} 10,18 / 05 / 2001, \mathrm{~F} .38$.

${ }^{31}$ Acta $\mathrm{N}^{\circ} 10,18 / 05 / 2001$, F. 38.
} 
“A la empresa Zanón la venimos corriendo y ya tenemos una nueva comisión interna pero nos tenemos que preparar porque en el futuro las empresas se nos van a venir encima.",32

Raúl Godoy (PTS), con la mirada puesta en sacar al conflicto de la provincia, complementa la opinión de Acuña:

"Para que no demos un paso en falso tenemos que tener organización, por eso Acuña además de ser el secretario de prensa tendrá que tener toda la documentación que salga en los medios para informar a los compañeros; López tendrá que hacer reuniones en las fábricas informando a los trabajadores de los temas gremiales que están pasando a nivel nacional, y lo más importante, seguir con la Mesa Coordinadora." ${ }^{33}$

El énfasis puesto por Godoy en la Mesa Coordinadora ("lo más importante") tiene que ver con la impronta que comienza a insuflarle a la dirección del conflicto la intervención de la izquierda desde el SOECN y que se percibe claramente en la urgencia por el armado de alianzas. Comienzan así una serie de viajes a regiones en proceso de organización y lucha como Tartagal o Río Turbio, y a provincias como Córdoba donde reciben la solidaridad del sindicato gráfico, ADIUC (docentes universitarios) y dirigentes del cuerpo de delegados de Luz y Fuerza. El SOECN apuesta a nacionalizar el conflicto buscando apoyos en Buenos Aires, donde se envía durante setiembre de 2001 una delegación de 100 ceramistas a manifestar en la sede de la empresa (Vicente López), mientras la planta era ocupada durante casi todo el mes. En el clima de movilizaciones y politización social que caracterizó al país durante el 2001, el SOECN decide consolidar un polo activista conformando la Coordinadora de Gremios, comisiones internas, activistas, delegados, organizaciones de desocupados y partidos de izquierda que luego se denominará "Coordinadora Regional Alto Valle". Su organización previa, el Comité de Lucha de Centenario, luego la Mesa por la Coordinación Obrera, fue interpretada desde una perspectiva política leninista de tipo "amplio frente único de sindicatos" 34 y la integraron el SOECN, el sindicato de televisión, la seccional Centenario de ATEN, la rama salud de ATE, agrupaciones de docentes de la ciudad de Cipolletti, la lista Naranja de la UOCRA y movimientos de desocupados, entre ellos el más numeroso y enraizado en la provincia, el MTD-Neuquén, y partidos de izquierda como el MST, POR, PTS.

La Mesa convoca a un acto para el 4 de agosto del 2001 en el comedor universitario de la UNCo que aglutina 700 participantes $^{35}$, siendo sus principales convocantes el SOECN y ATEN

\footnotetext{
32 Acta $\mathrm{N}^{\circ} 10,18 / 05 / 2001$, F. 39.

33 Acta $\mathrm{N}^{\circ} 10,18 / 05 / 2001, \mathrm{~F} .43$, negritas nuestras.

${ }^{34}$ La política de frente único tiene que ver con la concepción leninista del PTS para su intervención en sindicatos y se explica bajo el lema de "golpear juntos, marchar separados", es decir, mantener la independencia política y las críticas hacia otras organizaciones con las cuales se confluye en acciones en común, al tiempo que se practica la coordinación con los movimientos y organizaciones combativas. En caso de acciones conjuntas con sindicatos a los cuales los propulsores del frente único aplican la caracterización de "burocratizados", tales como el CTA en el caso neuquino, el frente único busca la posibilidad de discusión con las bases combinando exigencia y denuncia a las conducciones del CTA que están, desde la visión de la Coordinadora, "en tregua" con el gobierno.

${ }^{35}$ Estuvieron presentes: 80 obreros ceramistas de las 4 cerámicas, docentes de las seccionales ATEN Capital, Plottier y Centenario, miembros de la Comisión Interna del Hospital Castro Rendón, dirigentes del Sindicato de Televisión de la provincia, desocupados del Barrio San Lorenzo, del Barrio Islas Malvinas y de Cutral Có, el Secretario General de ADUNC (sindicato docente de la Universidad del Comahue) y dirigente la CCC, HIJOS Alto Valle y una delegación de la Corriente de Militantes por los Derechos Humanos, que a su vez trajeron la adhesión de la Red Patagónica de Derechos Humanos, ex miembros de la Coordinadora de Desocupados, trabajadores municipales, ex dirigentes de la UOCRA como Alcides Christiansen, el "Vasco" Etchebaster y Juan Yáñez, Aurelio Vázquez, dirigente de la UNTER (docentes de Río Negro) y representante del MAS, y una delegación del Centro de Estudiantes de Ciencias de la Educación (Cipolletti). De otras provincias: la delegación de Córdoba, un miembro de la Comisión Directiva del Sindicato de los Municipales de Córdoba, y de la Comisión Directiva de la Asociación de
} 
seccional Centenario $^{36}$. En ese acto nace la Coordinadora Regional Alto Valle y Neuquén. Su posicionamiento definirá las luchas políticas que mantendrá a futuro principalmente con su rival en las movilizaciones de $2001 \mathrm{en}$ adelante: la CTA, protagonista también de fuertes acciones durante el período y principal propulsora del FRENAPO (Frente Nacional contra la Pobreza) en diciembre de $2001^{37}$.

El lanzamiento efectivo de la Coordinadora ocurre en el acto del 1 de mayo de 2002 donde se logra reunir a 1000 activistas, duplicando el acto organizado el mismo día por el CTA. Las pugnas entre el SOECN y la CTA obedecen a una clara diferenciación ideológica y estratégica; la CTA es el modelo que representa a la vertiente "nacional popular" del sindicalismo político argentino que proviene de una revisión crítica sobre el movimiento peronista, aunque sin renegar completamente de aquella tradición. Su lema histórico fue "por un nuevo modelo sindical" autónomo del poder económico, con democracia sindical y apertura a otras organizaciones sociales, en especial los desocupados, de allí su otro lema paradigmático: "la fábrica es el barrio", creando las primeras organizaciones de desocupados dentro de una central sindical ${ }^{38}$.

A su turno, el SOECN ya muestra rasgos que indican que el camino es la conformación de un sindicato clasista en sentido que indica la tradición histórica, claramente influenciado por la izquierda dura, esto es, guiado la idea de independencia de clase: de allí su rechazo a efectuar alianzas con organizaciones patronales o con sectores de la pequeña burguesía (como lo practica el CTA) pero también reacio a depositar expectativas en el accionar del Estado y que además busca combatir las vertientes que considera burocratizadas en el movimiento obrero, entre las que suele ubicar a la mismísima CTA. Vale decir, lo "nacional popular" acá se presenta incompatible con el incipiente clasismo; la diferencia existe en tanto se trazan dos modos de comprender el armado de alianzas populares y en tanto (o porque) compiten al interior de los obreros más politizados dos ideologías: nacional-populista o centro-izquierda versus izquierda clasista. Ambas constituyen no obstante, diversas modalidades de concebir la ampliación organizativa (y sus límites tolerables), la estrategia, el sujeto que hegemoniza alianzas, etcétera ${ }^{39}$. Veamos cómo sigue el SOECN.

Docentes e Investigadores de la Universidad de Córdoba, Rubén "Pollo" Sobrero, Secretario General de la Seccional Oeste de la Unión Ferroviaria y Graciela Calderón, miembro de la Comisión Directiva del SUTEBA de La Matanza.

${ }^{36}$ A su turno, el antecedente de la Mesa Coordinadora es la Mesa de Coordinación de Centenario, surgida, según palabras de un activista docente de esa ciudad, en virtud de: “...la lucha de los obreros de Zanón. La necesidad de quebrar el aislamiento nos llevó en primer lugar a formar una coordinadora que tenía mucho peso lo territorial (la proximidad de Centenario a Zanón) y por eso la primera alianza fue entre el SOECN y Aten Centenario y después se fue ampliando. Este es el verdadero origen de la coordinadora del Alto Valle". La Verdad Obrera, órgano del PTS, 07/08/2002.

37 En el FRENAPO, de carácter policlasista, confluían, además del CTA, APYME (Asamblea de Pequeños y Medianos Empresarios), el Instituto Movilizador de Fondos Cooperativos, la Federación Agraria Argentina, Abuelas de Plaza de Mayo, Madres de Plaza de Mayo Línea Fundadora, el MEDH (Movimiento Ecuménico por los Derechos Humanos), el SERPAJ (Servicio Paz y Justicia), CELS (Centro de Estudios Legales y Sociales). Además, participaban de la Junta promotora el padre Luis Farinello, los obispos metodistas Federico Pagura y Aldo Echegoyen, la hermana Marta Pelloni, el rabino Daniel Goldman, de la Comunidad Bet El, Antonio Forte, por la Mesa Coordinadora Nacional de Jubilados y Pensionados, entre otros.

${ }^{38}$ Ver Armelino, Martín, "Kind of blue. Las vicisitudes de la Central de Trabajadores de la Argentina (CTA) durante los años kirchneristas", en Pérez, Germán y Ana Natalucci, (eds.), Vamos las bandas. Organizaciones y militancia kirchnerista, Buenos Aires, Nueva Trilce, 2012.

${ }^{39}$ Cabe aclarar que al interior del universo trotskista existen fuertes divergencias en cómo concebir el "frente único" y en quiénes pueden integrarlo y para qué. En el caso del SOECN y su política hacia afuera de la fábrica los choques entre el PTS y el PO (Partido Obrero, el mayor rival político del PTS) surgieron precisamente al inicio de la conformación de la Coordinadora, impulsada por el PTS pero rechazada por el PO que sostenía el argumento de que dicho llamado era "divisionista" respecto del CTA. Ver periódico La Verdad Obrera, órgano del PTS, 07/08/2002 en polémica con Prensa Obrera, órgano del PO, 19/07/2002. 
Entre octubre y fines de diciembre del 2001 la fábrica es ocupada intermitentemente por los ceramistas, mientras se fortalecen las alianzas en dos sentidos: 1) el intento de articulación regional y nacional de corrientes denominadas "antiburocráticas" y "antipatronales" bajo el liderazgo del SOECN a través de la Coordinadora ${ }^{40}$, 2) la política de acercamiento del SOECN con organizaciones de desocupados, en especial el Movimiento de Trabajadores Desocupados de Neuquén (MTD).

Legitimada en la concepción de "unidad de ocupados y desocupados", la alianza del MTD con los ceramistas va a tener lugar dentro de un marco que los liga como parte de la "clase trabajadora" "41. Sin embargo, la afinidad del SOECN-MTD no es aleatoria y se explica mediante la indagación en redes militantes de izquierda preexistentes: el MTD neuquino agrupa a desocupados que provienen del mundo de la construcción, como también a petroleros, telefónicos y otros ex empleados de empresas privatizadas que en el año 1995 organizaron la primera Coordinadora de Desocupados de Neuquén, cuyas raíces se despliegan hacia atrás, en lo que dejó la experiencia de lucha y organización de la UOCRA neuquina durante los '80, la cual desarrolló un intenso proceso de luchas que posibilitó descabezar a la anterior conducción sindical y la reemplazó por otra combativa, cuya cúpula contó con dirigentes del $\mathrm{MAS}^{42}$. A estos dirigentes posteriormente los encontraremos en el MTD organizando el movimiento y planteando la unidad con sectores obreros, para lo cual visitarán las fábricas en busca de alianzas, en especial Zanón. Varios jóvenes del MTD obtendrán su primer trabajo en Zanón, aprenderán a realizar boletines, ${ }^{43}$ a participar y foguearse en las asambleas piqueteras nacionales, entre otras actividades. Y las publicaciones periódicas y boletines informativos constituyen una práctica tanto de delimitación de una frontera política como un medio de homogeneización ideológica que permite demarcar la estrategia de la Coordinadora frente al CTA, que ya a esta altura del desarrollo del conflicto comienza a ser acusada de estar practicando una "tregua" en las acciones de lucha ${ }^{44}$. En este juego de alianzas y afinidades el MTD romperá, como era de esperar, una fugaz armonía previa con el CTA durante el inmediato post 2001, momento en que son invitados por esta central sindical a las primeras Asambleas Nacionales de Organizaciones Populares Territoriales y de Desocupados en La Matanza (Buenos Aires), de donde regresaron con fuertes cuestionamientos al modo en que ATE dirigía ese espacio militante. ${ }^{45}$

\section{Control obrero como acción innovadora}

Durante la ocupación de la fábrica (setiembre de 2001), los obreros se deciden a encender los hornos (que la empresa había decidido apagar) para demostrar con cuánto material producido era posible pagar los salarios adeudados de la planta entera. Para legitimar esta afrenta a la patronal, los obreros despliegan sus argumentos:

\footnotetext{
${ }^{40}$ Ver Boletin Nacional del Movimiento por la Coordinación Obrera, agosto de 2001.

${ }^{41}$ El MTD fue la organización de desocupados más poderosa de Neuquén y la que poseía más miembros: de 1300 integrantes en el año 2001 asciende a 3000 en el año 2003, más de 2/3 de ellos perciban subsidios Jefes y Jefas de Hogar, además de contar con una pequeña fábrica de adoquines destinados a obras públicas. Su sede estaba ubicada en el barrio más populoso del Gran Neuquén, el barrio San Lorenzo, que es también la única comisión vecinal que no controlaba el MPN. El MTD contaba además con delegados pertenecientes a otros nueve barrios. Ver Bonifacio, Mases, Taranda "Procesos de constitución de los movimientos piqueteros en la Provincia de Neuquén", en revista Estudios Sociales 25, Santa Fe, UNL, año XIII, 2003.

42 Sobre el MAS ver la nota al pie 24.

43 Ver por ejemplo, "La fuerza de la unidad", Boletín del MTD, número 1, fines de 2001 y el reportaje a "Pepe" y Eduardo, jóvenes del MTD ingresados a Zanón, en Revista Lucha de Clases, número 1, segunda época, noviembre de 2002

${ }^{44}$ Boletín de lucha, número 4, 19/10/01.

45 Ver Bonifacio, Luis Protesta y Organización. Los trabajadores desocupados en la provincia de Neuquén. Buenos Aires, Ed. El Colectivo, 2011.
} 
"Los trabajadores decidimos en forma democrática, como acostumbramos con nuestro sindicato y comisión interna, que ocuparíamos las instalaciones para mantener los hornos encendidos y comenzaríamos a producir con la materia prima existente que alcanza para un mes." 46

Este desafío hizo que el empresario Luis Zanón acuda a la instancia judicial y con su aval se apaguen los hornos definitivamente cortando el suministro de gas a la fábrica ${ }^{47}$ y luego iniciar la medida de presión que acompañará a los obreros en su largo periplo de lucha: la Justicia los intima a desalojar la planta. Pero los intentos de desalojo nos permitirán ver en el centro de la escena el arco de alianzas que se reconfigura en torno a la comisión de defensa de la fábrica, compuesta por los gremios y organizaciones denominadas combativas, las que desplegarán desde recitales en la puerta de la fábrica, fondos de huelga, peñas solidarias, comunicados de prensa, cortes intermitentes sobre la Ruta 7, actos con figuras reconocidas a nivel nacional, reuniones con el Consejo Deliberante de Centenario para desautorizar el desalojo, pedidos de audiencia a los bloques de la Legislatura Provincial, entre numerosas acciones diarias. En combinación con estas acciones el SOECN incrementa su participación en marchas de estatales neuquinos y unifica sus demandas: "por el no pago en Lecop y el no descuento del 13\% y la exigencia de estatización sin pago bajo control obrero" 48 y avanza en nuevas prácticas de solidaridad que incrementarán su legitimidad como lucha popular: a fines de diciembre del 2001 los ceramistas decidirán donar parte del stock con el que ya pagan sus salarios a una sala de laboratorio del Hospital de Centenario; más adelante repetirán en numerosas ocasiones el sistema de donaciones a hospitales, escuelas y "tomas" de terrenos cercanas a la fábrica, demandando un "plan de obras públicas" que genere "trabajo genuino", incorporando con esa consigna las demandas del MTD. Estas donaciones abren y legitiman también la opción del control obrero que además de ser enunciado en las demandas comienza a emerger como única alternativa al agotamiento del stock de cerámicos en la fábrica Zanón y que la justicia había autorizado a comercializar para cubrir los salarios adeudados. Mientras el control obrero ya circula como un rumor fuerte entre los trabajadores de Zanón, el empresario Luis Zanón lanza una propuesta o "plan de reactivación" con la reincorporación de 62 obreros, propuesta que es rechazada en asamblea. En consecuencia, a inicios de marzo de 2002 el control obrero es proclamado. Así lo enuncia Godoy en una asamblea del SOECN:

"En asamblea realizada en Zanón el día primero de marzo del 2002 se resolvió por unanimidad de los presentes poner la fábrica Zanón a producir bajo control obrero, con un sueldo de $\$ 800$, para cada uno de los compañeros y trabajar en los sectores con los coordinadores quienes cobrarán lo mismo.",49

Como se puede observar, varias prácticas remiten a un proceso que puede considerarse como democratización de prácticas sindicales (en especial, la toma de decisiones en asamblea, el criterio salarial igualitario) y que implican simultáneamente a las prácticas clasistas, a las que se agrega la innovación de la autogestión o control obrero. Esta última noción distingue tanto la experiencia en Zanón como la estrategia que asumirá desde entonces el SOECN diferenciándose del resto de la denominadas "fábricas recuperadas" que ya optan por el formato cooperativo. En este sentido, cuando se innove en otras actividades el criterio de clase, esto es, autoorganizado, de base, decidido por los propios obreros, y por lo mismo, clasista, logra transformar sentidos. Por ejemplo, es lo que ocurre cuando se comienzan a organizar recitales solidarios en la fábrica Zanón a beneficio de ésta y también de Cerámica Del Valle: "no habiendo desmanes ni agresiones de ningún tipo,

\footnotetext{
46 Boletín informativo del SOECN, 19 de octubre de 2001.

47 Mientras tanto, los estudiantes secundarios de Centenario, convocados por ATEN, habían realizado un abrazo solidario a la fábrica junto a los ceramistas

48 Acta $\mathrm{N}^{\circ} 18,22 / 12 / 2001, \mathrm{~F} .65$.

${ }^{49}$ Acta N ${ }^{\circ}$ 21, 30/03/2002, F. 73.
} 
con sólo seguridad obrera" ${ }^{50}$ La ausencia de desmanes y de agresiones implica la posibilidad de que el espectáculo sea concebido dentro de un marco de solidaridad con la lucha obrera, donde es el público el que, con una entrada económicamente accesible, disfruta del mismo y a la vez colabora con la experiencia. En un sentido similar, la idea de "seguridad obrera” es una práctica inaugurada por los ceramistas de Zanón y que establece un contrapoder al policial-estatal, ideológicamente opuesto a la idea dominante de "seguridad": la "seguridad obrera" no es una fuerza armada de represión ni el sostén institucional del orden social, sino que representa la posibilidad de construir una legalidad autónoma cuyas raíces, legitimidad y razón de ser hunden en la experiencia de lucha obrera y que puede pensarse de manera no muy distinta a la seguridad que las organizaciones militantes disponen para evitar infiltrados o provocadores en las movilizaciones; para estos casos los obreros elaboraron la idea de "disciplina ceramista", o cuando sus dirigentes reciban amenazas de muerte sospechadas de complicidad policial, se hablará de derecho a la "autodefensa obrera", concepto que también permite ver la profunda imbricación con la militancia de izquierda. Pero además, la lucha ceramista opera también como condición de posibilidad de que otros sectores invisibilizados (incluso dentro de la estrategia de los partidos de izquierda) y que sufren distintos tipos de agravios expresen su solidaridad a la vez que unifican demandas confluyendo en la caracterización del enemigo; tal el caso de la comunidad mapuce que ofrece a los ceramistas sus canteras de arcilla para apuntalar la producción bajo control obrero. Esta solidaridad genera como contrapartida la producción de cerámicos con nombres de referentes mapuce que resistieron al dominio del Estado argentino.

Al hostigamiento judicial y empresarial hay que agregar el apoyo explícito que el gobernador de Neuquén, Jorge Sobisch (MPN) y sus funcionarios, brindan a Luis Zanón acompañando las denuncias de éste contra los ceramistas. En medio de esta oscura complicidad suceden amenazas de muerte a dirigentes del SOECN, persecuciones con móviles policiales y robos a obreros encargados de la liquidación de sueldos. Este panorama represivo acentuará los contornos de una nueva etapa represiva que afectará las alianzas y acciones ceramistas poniéndoles un límite provisorio a su horizonte expansivo.

\section{Represión, desmovilización y ocaso de la Coordinadora Regional, 2002-2003}

A poco de ocurrido un asalto a obreros ceramistas encargados de la liquidación de sueldos de cerámica Zanón, el 23 de mayo del 2002 Raúl Godoy es citado a declarar por un corte de ruta, mientras que desde la embajada de Italia llega una carta que señala que Zanón ha sido ocupada "por un grupo minoritario de activistas que impiden el libre acceso a los trabajadores" que es reforzada nuevamente por intervenciones públicas del gobernador Sobisch denunciando la falta de "seguridad jurídica" en la fábrica. El clima hostil hacia la experiencia ceramista se comprende dentro de la escalada represiva que especialmente se cierne sobre los movimientos de desocupados a nivel nacional durante la presidencia de Eduardo Duhalde y que tendrá en junio del 2002 su punto de inflexión cuando ocurran los asesinatos a manos de la policía de dos militantes piqueteros, Darío Santillán y Maximiliano Kosteki, conocidos como la "masacre de Avellaneda".

Para rechazar nuevas denuncias e intentar consolidar y legitimar el arranque del control obrero el SOECN elabora un proyecto de "Administración Obrera Transitoria" y firma un "Convenio Marco" de colaboración con otro gran aliado estratégico: la Universidad Nacional del Comahue quien a través de distintos especialistas de economía y derecho proponen garantizar a través de

\footnotetext{
${ }^{50}$ Acta N¹8, 22/12/2001, F. 74. Los recitales en Zanón están a cargo de artistas y bandas populares como León Gieco, Bersuit Vergarabat, Manu Chao, entre otros, y participan entre 5.000 y 10.000 personas.

51 Acta $\mathrm{N}^{\circ} 23,22 / 05 / 2002$ F. 80.
} 
un plan de trabajo la incipiente gestión obrera ${ }^{52}$. La presentación de este proyecto se hace en la Legislatura neuquina y también en el comedor de la fábrica, lugar donde se anuncia la incorporación de los primeros diez nuevos puestos de trabajo destinados a miembros de organizaciones de desocupados que mostraron diversos grados de apoyo al SOECN: MTD, Movimiento Teresa Vive (vertiente del Movimiento Socialista de Trabajadores), Polo Obrero (vertiente del Partido Obrero) y Barrios de Pie (brazo de Patria Libre, corriente nacionalpopulista que luego apoyará la gestión del presidente Kirchner). El arco de organizaciones muestra también la flexibilidad táctica que exige el momento pues se propone desde el SOECN el ingreso de militantes de corrientes nacional populares (Barrios de Pie) hasta el rival más enconado del PTS, el PO a través de su organización de desocupados: el Polo Obrero.

Las restantes cerámicas del SOECN intentarán replicar algunas prácticas de Zanón, como por ejemplo Stefani, donde sus trabajadores logran el embargo del material para poder venderlo y cubrir los salarios adeudados (noviembre de 2002), o Cerámica Del Valle, cuyo dueño, Miguel Winter, a fines de enero de 2003 despide a todos sus obreros. Esta situación de despidos refuerza la visión estratégica que el SOECN plantea con organizaciones de desocupados por lo que realiza numerosas acciones en especial durante el año 2003 bajo la bandera de la Coordinadora Regional Alto Valle exigiendo la estatización de Zanón, el aumento de los Planes Jefes y Jefas de Hogar, la reapertura de padrones para incluir nuevos desocupados y por trabajo genuino. Otra dirección respecto de las alianzas ocurre con las demás fábricas recuperadas que se comienzan a organizar mediante encuentros en distintos puntos del país, aunque cierta afinidad entre algunas de ellas indique mejor los nexos entre el activismo de izquierda que una vocación de alianzas sin distingos, como por ejemplo el Pre-encuentro de Fábricas ocupadas realizado el sábado 15 de Febrero en las instalaciones de la Textil Brukman de Buenos Aires (influenciada en ese entonces por el PTS), convocado por Zanón-Brukman y Supermercado El Tigre, donde el SOECN envía 40 ceramistas $^{53}$.

Mientras, el gobernador Sobisch será reelecto (2003-2007) en el mismo año en que se lanza como candidato a la presidencia exteriorizando un perfil de político inflexible frente al clima de protesta social en todo el país; en particular su modo de deslegitimar la protesta será enturbiando las políticas sociales para con los desocupados, calificándolos como un sector manipulado por punteros políticos y cuyo modus operandi es el corte de ruta que ya comienza a ser tildado de ilegítimo y antidemocrático por el grueso de las clase gobernante y sectores de clase media en franca desmovilización. En palabras de Svampa ${ }^{54}$, es el inicio de las demandas de "normalización institucional", donde las formas de acción directa comienzan a ser neutralizadas ya por represión estatal, ya por cooptación de sus dirigentes por el Estado, ya por expectativas que abre el nuevo ciclo político a nivel nacional. En Neuquén el MPN lanzará una ofensiva contra las organizaciones de desocupados, buscando desprestigiar a sus dirigentes bajo los argumentos de que construyen su liderazgo con el manejo clientelar de subsidios y planes sociales: el 25 de noviembre de 2003, una feroz represión buscaba escarmentar principalmente a miembros del MTD que protestaban por el intento de Sobisch de bancarizar el cobro de sus planes sociales: la medida buscaba, según el gobierno, terminar con los intermediarios en el cobro de subsidios reempadronando con tarjetas electrónicas a casi 25.000 beneficiarios. La medida fue rechazada por el MTD y el CTA, quienes veían que detrás del empadronamiento se buscaba una reducción de beneficiarios y por lo tanto reclamaban "trabajo genuino". Al movilizarse hacia el Estadio Ruca Che en la mañana del 25 de noviembre, lugar citado para el reempadronamiento, son reprimidos por la policía terminando luego de casi un día de persecuciones policiales con 9

\footnotetext{
52 Acta $\mathrm{N}^{\circ} 29,30 / 11 / 2002, \mathrm{~F} .100$.

53 Según datos de los organizadores, al encuentro asistieron 2000 delegados de todo el país. Ver Acta $\mathrm{N}^{\circ} 34$, 12/04/2003, F. 116.

${ }^{54}$ Svampa, Maristella Cambio de época. Movimientos sociales y poder político. Buenos Aires, Siglo XXI, 2008.
} 
heridos de bala de plomo, 30 heridos y 6 detenidos. Entre los heridos con balas de plomo se cuentan a Heriberto Chureo, dirigente del MTD, y entre los que recibieron balas de goma se encuentran el entonces legislador provincial por Barrios de Pie, Jesús Escobar y el secretario general de ATE, Horacio Fernández. ${ }^{55}$ Pero quien fue objeto especial de la ira policial fue el joven José "Pepe" Alveal, quien pertenecía al MTD y había ingresado recientemente a Zanón. Recibió 64 balazos de goma perdiendo un ojo.

La brutal represión significó un antes y un después para el MTD ya que sus principales referentes, como el caso de Heriberto Chureo, quedaron muy afectados al persistir amenazas de muerte sobre su persona. Otro tanto ocurrió con lo que sería el comienzo de un largo derrotero judicial por encontrar a los responsables del alevoso ataque a "Pepe" Alveal, quien siguió trabajando en Zanón luego de una penosa recuperación física y emocional ${ }^{56}$. De resultas de esta escalada represiva, el MTD comenzará un rápido proceso de desmovilización cuyo efecto inmediato repercutirá en la Coordinadora Alto Valle y Neuquén, que perderá un pilar fundamental, y que anuncia su final como experiencia de coordinación entre ocupados y desocupados. Por su parte, el SOECN cierra filas en torno a Zanón, que inicia una nueva etapa consolidando el control obrero de cara a nuevos desafíos.

\section{Conclusiones provisorias}

¿Cómo comprender la trayectoria de politización del SOECN trazada hasta aquí? En sus inicios, para los obreros ceramistas contrarrestar su "experiencia burocrática" previa y superarla a través de la lucha les permitió la construcción de una identidad opuesta a aquella que fue enunciada bajo el imperio de un fuerte sentimiento antiburocrático. Este sentimiento no sólo identificó al burócrata sindical como enemigo sino que, fruto del proceso de lucha por defender la fuente laboral, incorporó en el mismo movimiento la recuperación del sindicato y la confrontación con la patronal como un todo. En otras palabras, el antiburocratismo sirvió para enmarcar este primer trayecto de lucha ceramista y contuvo en sus orígenes las características generales que se encuentran en el clasismo como tradición histórica: asambleísmo, honestidad de la dirigencia, perfil generacional, y a atravesando todo este proceso, el decisivo activismo de izquierdas, que le otorgó el plus de un perfil político combativo. Este perfil político se reforzó y alcanzó un "más allá del sindicato" cuando los obreros enfrentados a una patronal hostil reelaboraron una visión del orden social donde la metáfora de la guerra era la que mejor reflejaba ese antagonismo, permitiendo y reforzando la confluencia entre militantes independientes y partidarios; aún más, cuando arrecien amenazas de desalojo los antagonistas patronales harán bloque con el Estado. De allí que, para enfrentarlos, la construcción de una red de solidaridades se haga imprescindible y se traduzca en alianza estratégica, nuevamente en interacción con las definiciones políticas que aporta la izquierda, ya hegemónica en la conducción del SOECN: la idea de la Coordinadora de gremios combativos, sostenida por la izquierda en la fábrica, reafirma la identidad pero también delimita el horizonte de posibles aliados, y es allí cuando la CTA aparece como el modelo (o posición) sindical a competir (a diferenciar) ahondando la politización hacia un antiburocratismo radical, antipatronal, que asume rasgos novedosos como la alianza con el MTD o impactando más allá del SOECN abriendo el campo a las demandas de comunidades mapuce, no pensadas aún en el marco estratégico de las izquierdas.

\footnotetext{
55 Diario Río Negro, 26/11/2003.

56 Tras comprobarse la alevosía del hecho, dos policías recibieron penas de dos y cinco (año 2009). Luego se abrió otra causa por el maltrato recibido por "Pepe" luego de ser herido en dependencias policiales y por la negación a ofrecerle atención médica. Los imputados recibieron apenas dos años de prisión. La sentencia tardó siete años en llegar (año 2010).
} 
El salto más innovador de esta trayectoria inicial, en el sentido atribuido por McAdam, Tarrow y Tilly de introducir nuevas "perturbaciones en un campo interactivo", lo constituye sin dudas el inicio del control obrero, porque será la autogestión la que permita desplegar nuevas prácticas y significaciones ausentes en la tradición clasista: donaciones, lucha por "trabajo genuino", nociones de autodefensa y autonomía obrera, incorporación de nuevos trabajadores de organizaciones militantes, etcétera. Es quizás en este punto de la trayectoria y estrategia desplegadas por el SOECN donde puede comenzar a plantearse la pertinencia sobre un interrogante a discutir: $\dot{c}$ los rasgos descriptos se inscriben ya en un clasismo radical o mantienen elementos para hablar de sindicalismo de movimiento social? A juzgar por las características que presenta la trayectoria de politización de los ceramistas, y descontando el discurso utilizado por ellos, estaríamos frente a un claro caso de sindicalismo clasista con elementos que innovan aquella tradición.

Finalmente, la trayectoria de politización ceramista en el sentido de expansión de alianzas estratégicas encontrará un límite al no poder superar la represión estatal que produce un efecto desmovilizador sobre un aliado decisivo para el SOECN: el MTD. Se trata de un límite provisorio, claro está, pues la trayectoria de politización se extenderá en el tiempo adquiriendo otras características que requieren de nuevas indagaciones.

\section{Bibliografía:}

Abal Medina, Paula, Ser sólo un número más. Trabajadores jóvenes, grandes empresas y activismos sindicales en la Argentina actual, Buenos Aires, Biblos, 2014.

Aiziczon, Fernando, Zanón. Una experiencia de lucha obrera. Buenos Aires, Herramienta, 2009. Zanón. Fábrica sin patrones, Chile, ed. Escaparate, 2015

"El clasismo revisitado. La impronta del trotskismo en la politización del sindicato ceramista: Zanón Bajo Control Obrero, Neuquén 1998-2006”, en LabourAgain Publications, Nederlands, 2007, en: http://www.iisg.nl/labouragain/documents/aiziczon.pdf.

Armelino, Martín, "Kind of blue. Las vicisitudes de la Central de Trabajadores de la Argentina (CTA) durante los años kirchneristas", en Pérez, Germán y Ana Natalucci (eds.), Vamos las bandas. Organizaciones y militancia kirchnerista, Buenos Aires, Nueva Trilce, 2012.

Azteni, Mauricio y Ghigliani, Pablo, "The re-emergence of workplace based organisation as the new expression of conflict in Argentina”, en Gall, G., New Forms and Expressions of conflict at work, Palgrave Macmillan, 2013.

Azpiazu, Daniel y Basualdo, Eduardo, Cara y contracara de los grupos económicos. Estado y promoción industrial en Argentina. Buenos Aires, Ed. Cántaro, 1990.

Bourdieu, Pierre, Razones prácticas, España, Anagrama, 1977

Brennan, James, El Cordobazo. Buenos Aires, Sudamericana, 1996.

Bonifacio, Mases, Taranda "Procesos de constitución de los movimientos piqueteros en la Provincia de Neuquén”, Estudios Sociales 25, UNL, año XIII, Santa Fe, 2003.

-------- Protesta y Organización. Los trabajadores desocupados en la provincia de Nenquén. Buenos Aires, Ed. El Colectivo, 2011.

Bourdieu, Pierre, Razones prácticas. Sobre la teoría de la acción, Barcelona, Anagrama, 2007.

Duhalde, Santiago y Lenguita, Paula, El clasismo sindical en tiempo kirchneristas. Un estudio de caso, Conflicto Social, Año 5, No 7, Agosto, 2012.

Duval, Natalia Los sindicatos clasistas: SITRAC (1970-1971), Buenos Aires, CEAL, 1988.

Elbert, Rodolfo, "Activismo sindical y territorio en un período de reactivación de la protesta gremial en Argentina: Estudio de caso de trabajadores de un frigorífico ubicado en la zona norte del Gran Buenos Aires (2010-2011)", Quid 16, N²2 (181-192, 2012). 
Fajn, Gabriel Fábricas y empresas recuperadas. Protesta social, autogestión y rupturas en la subjetividad. Buenos Aires, Instituto Movilizador de Fondos Cooperativos, 2003.

Ferrero, Juan Pablo y Gurrera, María, "El sindicalismo de movimiento social. Algunas reflexiones en torno del concepto", en Fernández, A. (comp.) Estado y sindicatos en perspectiva latinoamericana. Buenos Aires, Prometeo, 2007.

Flores, Gregorio, SITRAC-SITRAM. La lucha del clasismo contra la burocracia sindical. Córdoba, ed. Espartaco, 2004.

Freire, Jorgelina, "La participación de las mujeres en las fábricas recuperadas: el caso de la Cerámica Zanón, Neuquén 2000-2006.”, Neuquén, 2008, disponible en: http://www.hechohistorico.com.ar/Trabajos/Jornadas $\% 20 \mathrm{de} \% 20$ Bariloche $\% 20$ $\% 202008 /$ Freire.pdf

Frege, Carola y Kelly, John, Union Revitalization Strategies in Comparative Perspective, London: European Journal of Industrial Relations, vol 9, 7-24, 2003.

Gordillo, Mónica, Córdoba en los '60: la experiencia del sindicalismo combativo. Córdoba, UNC, 1996. ---, Schmucler y Malecki (eds.). El obrerismo de pasado y presente. Documentos para un dossier (no publicado) sobre SiTraC-SiTraM. . La Plata, Ediciones Al Margen, 2009.

Kejner, Emilse, "Tomar la fábrica: producir alternativas. Análisis de las asambleas y las relaciones de género en los discursos fílmicos sobre Zanón - FaSinPat", en 3as Jornadas de Historia de la Patagonia San Carlos de Bariloche, 2008.

Löbbe, Héctor, La guerrilla fabril. Clase obrera e izquierda en la Coordinadora de Zona Norte del Gran Buenos Aires (1975-1976), Buenos Aires, Ediciones Razón y Revolución, 2006.

Novaes, Henrique, O fetiche da tecnologia: a experiência das fábricas recuperadas, Brasil, Expressão Popular, 2007.

Marticorena, Clara, Trabajo y negociación colectiva, Buenos Aires, Imago Mundi, 2015.

Moody, Kim, Workers in a Lean World. Unions in the International Economy. Londres, Verso, 1997.

Ortiz, María Laura, "Apuntes para una definición del clasismo", en revista Conflicto Social, Año 3, $\mathrm{N}^{\circ}$ 3, Junio 2010.

Palomino, Héctor, "Un nuevo indicador del Ministerio de Trabajo, Empleo y Seguridad Social: Los Conflictos Laborales en la Argentina 2006-2007”, Buenos Aires: Trabajo, Ocupación y Empleo, $\mathrm{N}^{0}$ 7, 2007.

Patrouilleau, Mercedes, "Historicidad e identidad colectiva en la gestión obrera de Zanón, Neuquén", Tesis de Maestría, Buenos Aires, UBA, 2009, disponible en: http://biblioteca.clacso.edu.ar/Argentina/iigguba/20130911022619/Patrouilleau Tesis.pdf

Programa Facultad Abierta, Las empresas recuperadas en la Argentina: Informe del segundo relevamiento del Programa Facultad Abierta. Buenos Aires, Secretaría de Extensión Universitaria, Facultad de Filosofía y Letras, UBA, 2005.

Rebón, Julián, La Empresa de la Autonomia: Trabajadores recuperando la producción. Buenos Aires, Ediciones Picaso, 2007.

Schumcler, Maleki, Gordillo, El obrerismo de pasado y presente. Documentos para un dossier (no publicado) sobre SITRAC-SITRAM. Buenos Aires, ediciones $\mathrm{Al}$ margen, 2010

Svampa, Maristella, Cambio de época. Movimientos sociales y poder político. Buenos Aires, Siglo XXI, 2008.

Tilly, Charles; Tarrow, Sidney y Mc Adam, Dough, Dynamics of contention, Cambridge University Press, 2001.

Upchurch, Martin y Mathers, Andy, "Neoliberal Globalization and Trade Unionism: Toward Radical Political Unionism”, en Critical Sociology 38 (2): 265-2870, London, 2011.

Varela, Paula, La disputa por la dignidad obrera. Sindicalismo de base fabril en la zona norte del Conurbano bonaerense, 2003-2014, Buenos Aires, Imago Mundi, 2015.

Werner, Ruth y Aguirre, Facundo, Insurgencia obrera en la Argentina (1969-1976). Clasismo, coordinadoras interfabriles y estrategias de la izquierda. Buenos Aires, Ediciones IPS, 2007 


\section{Documentos:}

Libro de Actas Junta Electoral SOECN.

Libro de Actas de Asambleas del SOECN, Ministerio de Trabajo, Formación y Empleo, Agencia Territorial Neuquén.

Boletin Nacional del Movimiento por la Coordinación Obrera, agosto de 2001.

Boletín de lucha, número 4, 19/10/01.

Boletin informativo del SOECN, 19 de octubre de 2001.

Registro de afiliados, Ministerio de Trabajo, Dirección Nacional de Asociaciones Gremiales, Departamento de Personerías e Inscripciones, FOCRA Neuquén, 1983, Tomo I. 